\title{
Applying general risk management principles to library administration
}

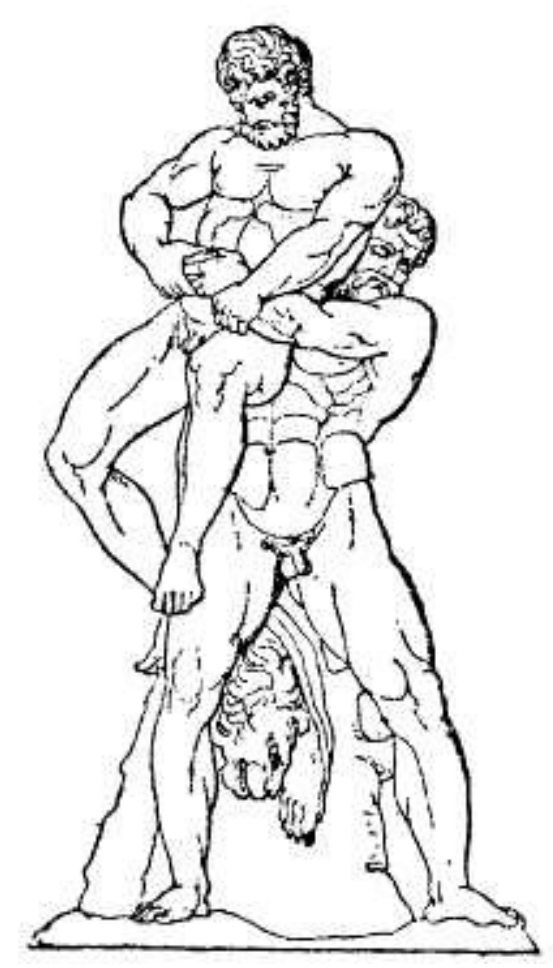

Heracles defeating Antaeus.

Public domain image: from the old Swedish encyclopedia Nordisk familjebok.

\footnotetext{
* The title of the 'Antaeus' column derives from the name of the mythical giant, Antaeus or Antaios. The son of Gaia (whose name means 'land' or 'earth'), Antaeus was undefeatable in combat so long as he remained in contact with the earth. Once grounded by contact with the soil, he vanquished all opponents. However, in order to disempower Antaeus, Heracles simply lifted him from the earth, overcoming him totally. Thus, many times through the centuries, Antaeus has been used as a symbolic figure showing how any human aspiration must remain grounded in order to succeed. LIS research must therefore retain its contact with the 'ground' of everyday practice in order to fulfil its potential as a sophisticated research discipline - it must remain empowered by its relevance to practitioners.
} 


\section{Applying general risk management principles to library administration}

\begin{tabular}{|c|c|}
\hline & Abstract \\
\hline Purpose of this paper & $\begin{array}{l}\text { Recent areas of digital library innovation, such as } \\
\text { digital rights management, have led librarians to apply } \\
\text { risk management (RM) principles to certain } \\
\text { circumscribed areas of library management. This } \\
\text { paper will attempt to argue that risk management } \\
\text { principles can in fact be applied much more generally } \\
\text { in modern library administration. }\end{array}$ \\
\hline Design/methodology/approach & $\begin{array}{l}\text { A conceptual paper based on abstract principles of risk } \\
\text { management. }\end{array}$ \\
\hline Findings & $\begin{array}{l}\text { That different approaches to risk management apply } \\
\text { in digital librarianship, as opposed to traditional, print- } \\
\text { based library work. Also, that different models of 'RM' } \\
\text { can be used at the level of the employee in contrast to } \\
\text { the global perspective of the organisation as a whole. }\end{array}$ \\
\hline $\begin{array}{l}\text { Research limitations/ } \\
\text { Implications }\end{array}$ & $\begin{array}{l}\text { Because this is a conceptual piece, there is ample } \\
\text { room for further experimental testing of these } \\
\text { hypotheses. }\end{array}$ \\
\hline Practical implications & $\begin{array}{l}\text { This paper rejects some of the principles of RM that } \\
\text { are less relevant to the 'people management' } \\
\text { problems of hybrid (print-electronic) library } \\
\text { administration. It offers an abstract statement of RM } \\
\text { principles that should be of genuine practical } \\
\text { usefulness to middle managers helping staff cope with } \\
\text { the problems of 'mixed media', hybrid library } \\
\text { environments. }\end{array}$ \\
\hline $\begin{array}{l}\text { What is original/value of the } \\
\text { paper? }\end{array}$ & $\begin{array}{l}\text { This paper relates ideas from general business risk } \\
\text { management to practitioner librarianship in ways that } \\
\text { have not been attempted previously. }\end{array}$ \\
\hline
\end{tabular}

Paper type: Conceptual paper

Keywords: Libraries; library management; risk assessment. 


\section{Introduction}

Recent areas of digital library innovation, such as digital rights management, have led librarians to dip their toes cautiously into the perilous waters of risk management (Joint, 2006; Seadle, 2006). We are starting to think that perhaps more than one or two limited areas of library work can be understood with the tools of 'RM'. Previously, user aggression towards library staff (Farrugia, 2002) and large scale library disasters such as fire or flood (Eden and Matthews, 1997) have been discussed before in terms of risk management in libraries. Digital library technology seems to be pushing the topic further into mainstream library work.

Of course, librarians are famously 'risk-averse'. But, just because you don't like something, doesn't mean you can ignore it - tentativeness in face of the reality of risk has to be misguided. Digital technology has changed most if not all aspects of the library world and in many ways it has made library work more 'risky'. So it is better to think about what can be done in a practical and helpful sense to offset things going wrong before they do go wrong. As a step towards bringing the phenomenon of risk into the risk-averse world of librarians, this paper will attempt to show how certain risk management principles might be applied quite generally to all aspects of library administration, while at the same time acknowledging the limitations of inappropriate risk management procedures.

\section{Management jargon}

Much of the copious literature of risk management is heavily biased towards corporate business interests, especially the financial and insurance sectors (Institute of Risk Management et al., 2002). This will tend to put librarians off looking at the literature.

It's not hard to see why. To the inexperienced reader, much of the literature of 'RM' appears rather overblown and shallow: there is a suspicion that the management consultants have found a new area of managerialist jargon with which to massage the anxieties of corporate executives. As we all know, management consultants use corporate anxiety as the lever that prises cash out of clients' bank accounts into their own bank accounts. Users of risk management jargon thus have a ready-made barrier of cynicism which they must cross - perhaps at no little 'risk' to themselves!

Just to emphasise this point, it is worth looking at the IRM's own risk management standard (op cit.). This is a collective work, authored by the IRM together with the Association of Insurance and Risk Managers and the evocatively named "ALARM", the National Forum for Risk Management in the Public Sector. What is a library manager to make of this offering?

One might start by noting pages three and four of this document, which display some of those unmemorable diagrams which consultants tend to use in Power Point demonstrations, inevitably promoting somnolence in the audience and parody from satirists such as Dilbert and their llk $^{1}$. The diagrams - as ever - are made up of lots of concept boxes, each linked to the other in various complex ways.

One may ask, what are such diagrams for? What really are the differences between terms in boxes such as 'risk estimation' and 'risk assessment'? Can 'risk analysis' really be broken down meaningfully into 'risk identification', 'risk description' and 'risk estimation'? Or is this proliferation of words simply the result of a desire to fill 
Power Point text boxes with as many phrases as possible that start 'risk'? These diagrams also show that Dilbertian need to have lots of arrows linking boxes. Arrows seem to create a sense of dynamism and movement, and show how to make things happen ---> fast!

Before our cynicism overwhelms us, we should acknowledge that, in fact, the vocabulary of risk is now enshrined in the International Standard PD ISO/IEC Guide $73: 2002$, which is some proof of the value of at least the terminology of risk management. We should not be unfairly sceptical.

So if information professionals want to know about risk techniques behind acronyms such as HAZOP, BPEST analysis and PESTLE, this is the standard to consult ${ }^{2}$. Librarians, read and take heed.

\section{Low Risk in Libraries}

Putting acronyms and jargon aside, what can be said simply and clearly about the nature of risk in libraries?

Firstly, most library work consists of sequences of procedures and processes, many of which, though potentially complex and challenging, can be described as quite low risk, individual operational tasks. Cataloguers will catalogue a number of items in a day, some of which may be quite tricky to do correctly, but the consequences of error are never cataclysmic. You may catalogue a book so badly that it is never retrieved from your collection, but the error could well be attributed to reader theft or miss-shelving. So, as long as your error is not part of a consistent and unrelenting pattern of incompetence, your error will pass unnoticed.

Reference staff may answer scores of enquiries in a day, but the consequences of one-off error will rarely be life-threatening, and will be unlikely to come back and haunt the librarian. Indeed mystery shopper tests of reference services have in certain incidences thrown up some quite glaring errors, which would not have incurred any risk of detection had the circumstances of investigation not been radically different during the one-off 'mystery shop'.

This is not to say that library work is not important or professional, nor are we saying that it should not be done well. But each self-contained task in the sequence of daily activity is not very risky: the financial well being or reputation of the host institution of the Library will not be threatened by any one mistake, nor will the life and limb of the librarian be endangered.

Risk in library environments can thus be characterised in two ways: for most staff, the risk represented by each task is low, and the level of risk does not vary, it is predictable and similar in each particular instance. Libraries thus present a Homogenous, Low risk environment.

In fact, most work environments are low risk for most workers - we would be a nation of valium addicts if it were not so. However, many workers have to be on the look out for rare moments of high risk, when they need to rise to a much greater level of endangerment, of things going wrong.

For example, driving a bus is like this: mostly humdrum, but with unpredictable moments of occasional, and exceptional risk - for example, when a pedestrian walks unexpectedly in front of the vehicle, when the life and limb of driver and passengers 
are in peril, and when the financial well being and reputation of the Bus company are at stake ('Family of blind pedestrian killed by inattentive bus driver sue driver and bus company for millions!').

Although this type of work is low risk, its riskiness is not always the same. It is a Heterogeneous, Low Risk environment.

\section{High risk work environments}

I will have to lapse into a moment of self-indulgent autobiography now, and use personal, anecdotal evidence to pursue the argument of this paper. I beg the reader's forgiveness for this, but it is a useful and illustrative lapse none the less.

My father's choice of work was extremely high risk: he was a film stuntman ${ }^{3}$. He was also a member of his trade union, part of Equity, the UK media performers' association. He was active in Health and Safety work for his union and was puzzled by the Health and Safety statistics for his trade. Ironically, in terms of incidences of harm per hours worked, the statistics for injury and death for British stuntmen were much better than for other occupations - for example, the UK building trade and British farming.

This was rather unfortunate when trying to argue for lucrative contracts for workers whose profession involved them in regularly jumping off cliffs, setting themselves on fire and riding motor bikes into walls. How could this be less risky than banging nails into wood, plumbing pipes and painting walls? Or herding sheep?

The difference lay in the nature of the risk environments concerned.

Some working environments are highly dangerous but still very predictable. Film stunt work is clearly like that, highly dangerous but very predictable: a script is written and a dangerous act planned. That act can be planned down to the last detail, the day and time on which it is to take place is known, so that all elements that need to be put into place to offset risk can be made. This is a Homogenous, if High Risk environment.

In contrast, building workers and farmers work in an environment which is less risky than a film stunt environment, but which is much more unpredictable - the daily nature of risk is heterogeneous. The working environment of a soldier on active service - often described as long periods of boredom punctuated by unpredictable moments of sheer terror - is understandably the most perilous in the world. But not because life on active service in the armed forces is simply High Risk. Rather, it is perilous because it is unpredictably risky, that is, it represents both a Heterogeneous and High Risk environment.

Heterogeneity is the crucial element therefore, rather than the degree of risk per se - in some ways it can be less perilous to work in a Homogenous, High Risk environment than in a Heterogeneous, Low Risk work environment. This is why building site workers experience a higher statistical rate of injury and accident than film stuntmen, despite the latter seeming to lead a life of greater peril than construction workers and plumbers.

Generalisations (plus a diagram): "Risk and heterogeneity"

Unfortunately, having previously been so rude about risk management diagrams with lines and arrows joining them, I am now going to offer a diagram of the structure of 
risk which I have elaborated above, just to formalise the general sense of what I have been saying. Please be grateful that at least I haven't included any arrows.

This is an $x-y$ axis diagram as used in coordinate geometry, where the centre of the graph where the two lines cross represents zero. Positive values above 0 (towards the right) on the horizontal $X$ axis represent increased degrees of risk, while positive values above 0 (nearer the top of the page) on the vertical $Y$ axis represent increased degrees of heterogeneity. Note: this mathematical grid is just a metaphor, and should not be taken too seriously, and above all, should never be used in a risk management Power Point demonstration!

'Safety' is thus a negative value, expressing the complete absence of unpredictable risk. It is a value represented at a coordinate to the extreme bottom left of the diagram, one inhabited by a box marked 'traditional librarian'! Inevitably, the polar opposite of a traditional librarian - a soldier on active service - is at the diagonal opposite of the diagram from the traditional librarian, the top right.

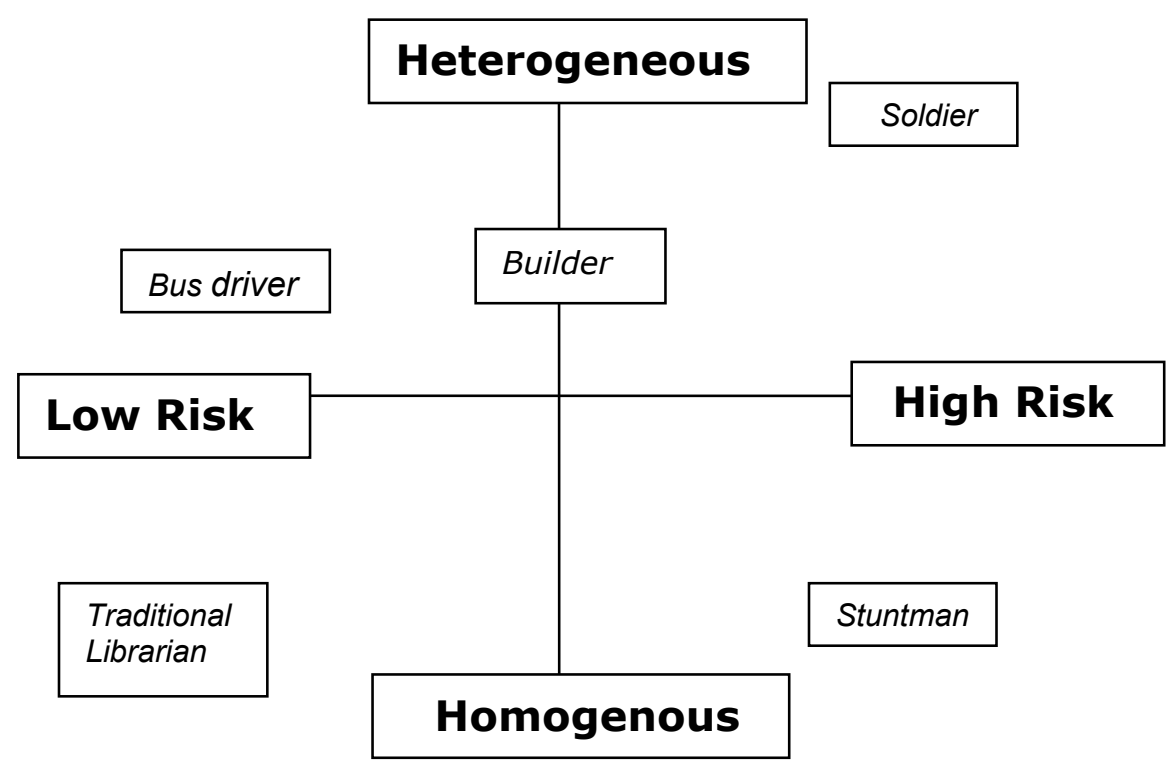

Figure 1: Diagram of risk and homogeneity (predictability) levels.

\section{"Risk and impact"}

To explain these ideas in a different way, this diagram is a 'binary antithesis' - a pair of opposites - rather like the more familiar 'binary antithesis' of risk management, where risk (high or low) and impact (high or low) are set off against each other. However, the model above does offer different insights from the risk versus impact 'binary antithesis' and these can help solve different problems in an organisation.

In the risk versus impact model, risk can be quantified numerically - for example, one can talk of 'a one in ten' risk of something going wrong in a certain type of work activity. The definition of degree of impact (high or low) is more subjective, but clearly if an activity is low risk - for example, with a 1 in 100 chance of going wrong yet involves risking one's own life, it is best avoided, even though it is unlikely to happen: one's own death is definitely a high impact event! By contrast, a 1 in 100 
chance of at worst stubbing your toe is a low risk, low impact scenario, one that even the most risk-averse librarian can feel comfortable with.

Nevertheless, if something is high risk, but low impact, then it might be worth doing. A travelling salesman might judge it worth doing something with a high risk of detection like driving constantly $25 \%$ over the speed limit regardless of speed cameras, if, in so doing they acquire enough business to make the difference between bankruptcy or financial viability. The risk of detection nowadays is high, but the impact of having speeding points added to one's licence is low, at least in the UK. (Please note that some of these calculations may seem offensively amoral - but these are not ethical statements, merely brutal calculations of risk, and I apologise if they seem callous.)

The risk/homogeneity and risk/impact models do differ in some important ways, however.

Note, for example, that in the risk/homogeneity model, the respective risk statuses of (say) an airline pilot and a stuntman are similar, but in the risk/impact model they are very different.

In the risk/impact model, a stuntman's work is constantly and pervasively risky, whereas an airline pilot's work is in practice only occasionally risky, at take-off and landing, which constitutes a small part of the working day. The stuntman is pervasively and constantly exposed to risk, whereas there is only a genuine risk of real disaster for the pilot at the start and end of their flight - say $1 \%$ of their working day. And certainly, when things go wrong in either case, the impact is high. Nevertheless, looked at from another angle, the homogeneity of their risk environment is what they have in common: they both know when to raise their game to control risk in their working life.

The main benefit of the risk/impact approach is in terms of overall, high level management of a large company or organisation - it enables you to quantify risk objectively across the company. For so many hours of employee activity, with a $1 / 10$ level of risk and a given number of employees, you can quantify the impact of risk in terms of insured liability, and then an accurate amount of money can be set aside to pay for the right amount of insured risk. This is a good way to manage risk at the aggregate level of the global organisation - a good tool for the remote company executive who does not line manage their staff personally.

In the risk/ homogeneity model, this form of risk analysis sees that both types of employments expose the worker to high impact risk (film stunts going wrong, planes crashing), but emphasises that these work activities do so in a predictable fashion, even though sitting in a cockpit on autopilot is much less risky than driving a car off a cliff. This model emphasises the similarity in these two types of work, whereas the risk/impact model would see them as being very different. But above all, it sees risk from the point of view of the employee, and that is a valuable perspective.

The most important benefit in perceiving that a risk environment is homogenous, rather than heterogeneous, is that it shows that risk is equally 'dealable with' from the subject's point of view, enabling the employee to plan and be mentally prepared to control moments of risk by training and preparation. The risk/ homogeneity model sees risk from the point of view of the employee managing their personal risk, rather than the high level manager managing corporate risk, who needs to set company 
resources aside to pay for something going wrong. This is a good way to manage risk at the individual level of the individual employee - a good tool for personal coaching, for the middle manager who has a lot of contact with his or her staff, and who wants to help them do their job better.

\section{Homogeneous low risk in traditional libraries}

So analysing risk by setting off risk against homogeneity/heterogeneity gives 'people' mangers a good way to understand how their staff can be best motivated to manage risk effectively in their work.

As we have said before, traditional librarians work in a very homogenous, low risk environment. This generates problems in terms of risk assessment and management at the level of the individual. Above all, there is a problem of generating a motivation to work well, when no one task is particularly risky.

For better or worse, fear of failure or catastrophic error does motivate the individual to work well. It's not the ideal motivating factor, nor thankfully is it the only motivating factor for an employee, but it is a very powerful one. However, like other workers in a homogenous, low risk environment, librarians, cannot 'benefit' from such a negative motivating factor.

Of course, positive motivating factors such as interest in one's work, commitment to user services, belief in organisational aims, and the like, can and do come into play, and undoubtedly these incentives have for centuries helped the LIS profession preserve high professional standards. But no reader or librarian has ever died as a result of indexing books on 'discrete mathematics' with guides to etiquette, or misshelving 'Moby Dick' at Marine Biology.

In which case, is the popular perception of LIS workers as highly anxious about the risk of error correct? In fact, it probably is. Perversely, it may be the case that traditional librarians cultivate an exaggerated sense of risk in order to provide a valuable negative incentive to work to a high standard. Their aversion to risk means that they see the consequences of any error as being much greater than they really are, and use this as a way of maintaining high standards.

\section{The risk environment of digital libraries}

However, the risk environment in digital libraries is different from the risk environment of traditional Libraries. In reality, both environments are low risk, but the digital library work environment is significantly more heterogeneous and unpredictable than the traditional library world. The consequences of digital library error are probably rather more 'impactful' than those of traditional library error, but both are broadly similar, being low risk, low impact environments. However, the risks that you run in digital libraries are much more unpredictable - digital library risks environments are not so homogenous.

As example, one could cite the risk of financial error in pay-for-view online searching, one of the first pervasive and definitively 'new' digital library tasks that emerged in the 1970's and 80's. I once had to deal with a librarian who had accidentally instructed an online search vendor to print off ALL of a search set in FULL format, but had indicated the wrong search set - a very large search set. The system started printing off thousands of records at some 50 cents per record.

Realising the error, the librarian switched their pc off, thinking that this cancelled the search command. Sadly not - over in California, home to the database host, 
thousands of records were being displayed, creating a bill for many thousands of dollars which caused quite a stir when it arrived at the end of the month.

As it turned out, an emollient phone call to the vendor explained the error and the bill was cancelled. But the librarian was traumatised. Despite being an excellent traditional librarian, and also an excellent online searcher with good command line searching skills and good interpersonal skills, they never wanted to do an online search again.

This is the unfortunate side of the traditional library approach to the risk of making a mistake. How do you, as a library, get the best out of highly talented library staff, when their attitude to risk, not their ability, can be a profound drawback?

By becoming hyper-sensitive to the dangers of making a mistake, we create strengths in terms of traditional library work, but inhibiting factors for digital library work. In reality, in the anecdote above, nothing went wrong - a bit of electricity was wasted in California. But the unexpected nature of the sudden appearance of risk (its 'heterogeneity') seemed deeply traumatic, as if a doctor had risked the life of a patient or a car had hit a wall.

The digital librarian thus needs a different mindset from the traditional librarian because they inhabit different risk environments (see Figure 2). Traditional librarians may benefit from being trained to recognise and apply this model, using it as a tool for dealing with the inhibiting sense of risk that they may bring to their digital work from their traditional work.

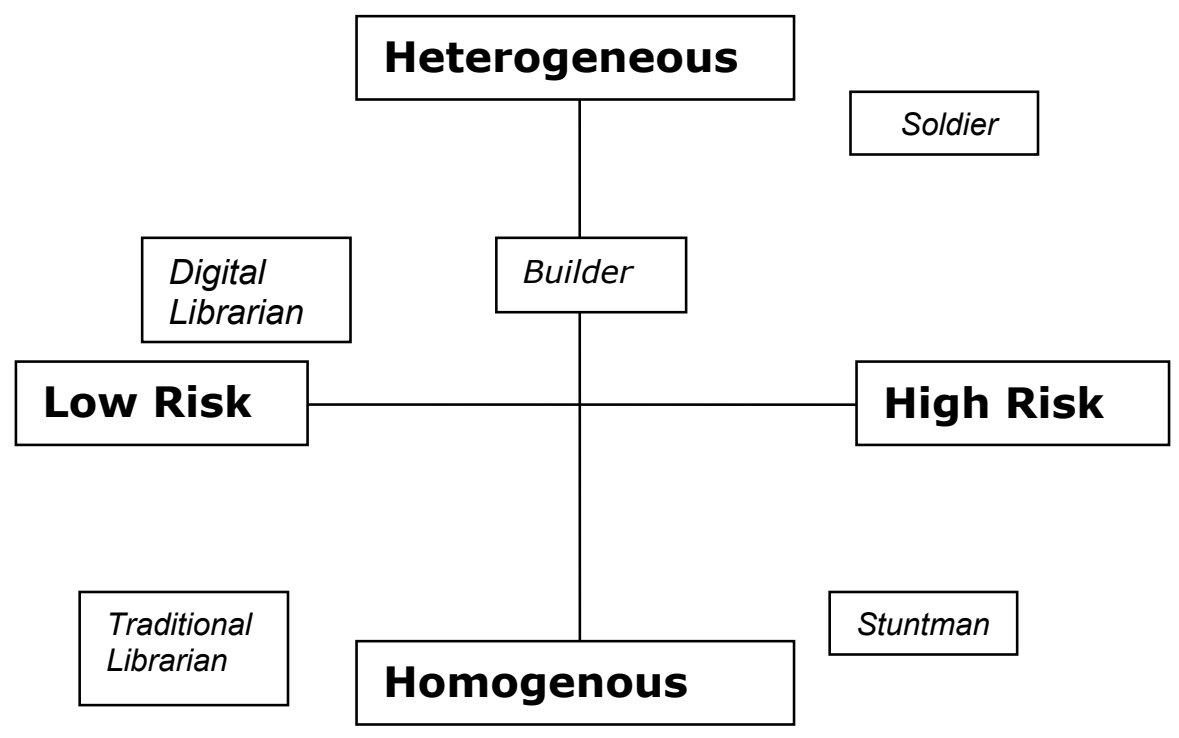

Figure 2: Risk and homogeneity (predictability) levels: the digital librarian versus the traditional librarian.

\section{Conclusion}

Much of the literature of risk management is rather remote from the concerns of the everyday employee or professional, because it deals with quantifying large-scale risk within big organisations (hence the opening sceptical approach to RM in this paper). 
It is nevertheless a very important and very valuable management tool for making sure that companies and institutions prepare for adversity, and have the financial backbone - adequate insurance - to deal with disaster.

This form of risk management can work well in large-scale digital library projects. The EThOS project ${ }^{4}$, for example, manages risk very intelligently and successfully in terms of the large-scale risk/impact models of 'RM' (Joint, op. cit.). A large library organisation such as the British Library can use received general business risk management principles quite successfully, just like any large business ${ }^{5}$.

However, individual employees' psychological perception of risk, and how they use their conceptualisation of risk in their day to day work is a very different phenomenon from the reality of 'aggregate' risk across a big organisation. A subjectively distorted sense of risk can be a perverse but powerful factor raising standards of work and inspiring dedication to duty (although one would never use it as a tool for calculating amounts of insured risk!).

Managers may well want to cultivate this sense of individual 'risk-sensitivity' in order to maintain high standards while knowing that the real nature of risk in their organisation is low - indeed, doing away with a subjectively enhanced sense of risk and fear of error may 'risk' lowering of standards in that organisation. A cataloguer or reference librarian who does not treat each individual task as if their career was at stake may find that a general slackness pervades all of their work. If no one specific task really matters, then one may start asking whether any of one's work really matters.

Once this virus of indifference take hold, then the risk is that corporate standards in a library plummet - and libraries are expensive organisations where pervasive low standards can waste enormous amounts of resources, for example, imperilling core educational outcomes in schools and universities. This is a chance, a real risk, that no manager would wish to take.

But the workplace changes fast in the modern world, and in order to understand how employees adapt to change library administrators needs to understand how individuals perceive risk in their personal working environment. Even more challenging is the fact that library managers now manage hybrid library environments, where staff often move quite regularly between traditional tasks and digital tasks. A different, more flexible mindset is needed for such hybrid library work - this is perhaps one of the greatest hurdles of human resource management and training in the modern library world.

This 'employee-centred' model of risk management may help achieve this degree of flexibility in library staff deployment. As such it is well worth considering alongside other principles of risk management that are currently more widely applied across a wide range of organisational contexts.

Nicholas Joint

Centre for Digital Library Research/

Andersonian Library

University of Strathclyde. 


\section{Notes}

1. Dilbert and risk management: a satirical cartoon.

$<$ http://plg.uwaterloo.ca/ migod/fun/dilbertriskmang.gif > Accessed 29/4/07.

2. HAZOP = Hazard and Operability Studies; BPEST analysis = Business, Political, Economic, Social, Technological analysis; PESTLE = Political, Economic, Social, Technical, Legal, Environmental (analysis).

3. Internet Movie Database: Imdb.com (entry for Alf Joint)

< http://www.imdb.com/name/nm0426996/ > Accessed 29/4/07.

4. The EThOS project. < http://www.ethos.ac.uk/ > Accessed 29/4/07.

5. British Library Risk Management policy statement.

< http://www.bl.uk/about/policies/riskmanagement.html > Accessed 29/4/07.

\section{References}

Eden, P. and Matthews, G. (1997) Disaster management in libraries Facilities $15: 1 / 2$ pp. $42-49$.

Farrugia, S. (2002) A dangerous occupation? Violence in public libraries. New Library World, 103:9 pp. $309-319$.

Institute of Risk Management et al. (2002) A risk management standard.

< http://www.theirm.org/publications/documents/Risk Management Standard 030820.pdf > Accessed 29/4/07.

Joint, N. (2006) Risk assessment and copyright in digital libraries.

Library Review, 55:9 pp. 545 - 548.

Seadle, M. (2006) Copyright in the networked world: copyright police.

Library Hi Tech, 24:1 pp. 153 - 159.

Received 26/4/07, reviewed 30/4/07, revised 1/5/07, accepted 7/5/07. 